\title{
Review Article \\ Postoperative Pulmonary Dysfunction and Mechanical Ventilation in Cardiac Surgery
}

\author{
Rafael Badenes, Angels Lozano, and F. Javier Belda \\ Department of Anesthesiology and Surgical Intensive Care, Hospital Clinic Universitari de Valencia, \\ University of Valencia, 46010 Valencia, Spain
}

Correspondence should be addressed to Rafael Badenes; rafaelbadenes@gmail.com

Received 5 December 2014; Revised 15 January 2015; Accepted 17 January 2015

Academic Editor: Djillali Annane

Copyright (c) 2015 Rafael Badenes et al. This is an open access article distributed under the Creative Commons Attribution License, which permits unrestricted use, distribution, and reproduction in any medium, provided the original work is properly cited.

Postoperative pulmonary dysfunction (PPD) is a frequent and significant complication after cardiac surgery. It contributes to morbidity and mortality and increases hospitalization stay and its associated costs. Its pathogenesis is not clear but it seems to be related to the development of a systemic inflammatory response with a subsequent pulmonary inflammation. Many factors have been described to contribute to this inflammatory response, including surgical procedure with sternotomy incision, effects of general anesthesia, topical cooling, and extracorporeal circulation (ECC) and mechanical ventilation (VM). Protective ventilation strategies can reduce the incidence of atelectasis (which still remains one of the principal causes of PDD) and pulmonary infections in surgical patients. In this way, the open lung approach (OLA), a protective ventilation strategy, has demonstrated attenuating the inflammatory response and improving gas exchange parameters and postoperative pulmonary functions with a better residual functional capacity (FRC) when compared with a conventional ventilatory strategy. Additionally, maintaining low frequency ventilation during ECC was shown to decrease the incidence of PDD after cardiac surgery, preserving lung function.

\section{Introduction}

Postoperative pulmonary dysfunction (PPD) is a quite common complication after cardiac surgery [1]; $40 \%$ of patients readmitted into intensive care units (ICU) present respiratory failure [2], and the adequate therapeutic management that might reduce its incidence is still unknown.

PPD pathophysiology is complex and its mechanisms are not clear (Table 1). Even so, there are many surgeryrelated factors that predispose cardiac surgical patients to the pathogenesis of postoperative pulmonary complications, such as the effects of general anaesthesia combined with the effects of median sternotomy incision, cardiopulmonary bypass (CBP), internal mammary artery dissection, and the use of topical cooling for myocardial protection [3].

PPD clinical manifestations include pleural effusion, with a frequent presentation (27-95\%) [4], and atelectasis (16.688\%) [5] and postoperative hypoxemia without clinical symptoms (3-10\%) [6] and acute respiratory distress syndrome (ARDS), which have a low incidence (0.5-1.7\%) [7] but high mortality (50-90\%) [8].
Furthermore, cardiac surgery produces a whole body inflammatory response that has been highly related with lung injury [9]. This systemic inflammatory response is associated with anomalies in gas exchange, such as an increased pulmonary shunt fraction [10], increased pulmonary vascular resistance [11], and intrapulmonary aggregation of leukocytes and platelets [12]; also with alterations in lung mechanics, resulting in a reduced pulmonary compliance and reduced functional residual capacity (FRC) and vital capacity (VC) or both of them.

\section{Factors Associated with the Development of PPD after Cardiac Surgery}

2.1. General Anesthesia. Is well known that lung functional impairment is inevitable after any major surgery, a condition that most likely is related to the general anesthesia.

There are many factors related with general anesthesia that affect pulmonary function. Anesthesia with the prolonged supine position produces an upward shift of the 
TABLE 1: Pathogenetic mechanisms of postoperative pulmonary dysfunction (PPD).

Specific to cardiac surgery:

(i) Median sternotomy incision

(ii) Use of cardiopulmonary bypass (CPB)

(iii) Transfusion of blood product

(iv) Topical cooling for myocardial protection

(v) Dissection of the internal mammary artery

(vi) Effects of general anesthesia

Anomalies in gas exchange:

(i) Widening of the alveolar-arterial oxygen gradient

(ii) Increased microvascular permeability in the lung

(iii) Increased pulmonary vascular resistance

(iv) Increased pulmonary shunt fraction

(v) Intrapulmonary aggregation of leukocytes and platelets

Alterations in lung mechanics:

(i) Reductions in vital capacity (VC)

(ii) Reduction of functional residual capacity (FRC)

(iii) Reduction of static and dynamic lung compliance

diaphragm; this, combined with the relaxation of the chest wall and altered chest wall compliance, and with the blood volume modification in the thorax, results in an alteration of the ventilation-perfusion mismatch and an abnormal pulmonary shunt fraction [13]. Furthermore, the majority of the drugs used in anesthesia also have repercussion in the pulmonary function; inhalation anesthetics, for example, inhibit hypoxic pulmonary vasoconstriction, and narcotics reduce hypoxic and hypercapnic ventilatory response.

All these combined factors result in a widened alveolararterial oxygen gradient [14] and a reduction of the vital capacity and the functional residual capacity of the lungs [13]; and it also contributes to the onset of hypoxemia and atelectasis [14].

\subsection{Extracorporeal Circulation (ECC). Extracorporeal cir-} culation (on-pump surgery) has clear consequences for postoperative pulmonary function. The vascular contribution to the lungs depends almost exclusively on the pulmonary arteries. The principal function of the bronchial circulation is to feed the pulmonary structures; thus, it is responsible for approximately $1 \%$ of the pulmonary circulation. However, when the arterial circulation is chronically compromised, the bronchial circulation takes on a leading role.

When ECC initiates, the cessation of pulmonary ventilation results in collapsed lungs with loss of surfactant and alveolar collapse, favouring the retention of secretions and atelectasis. Moreover, pulmonary circulation is stopped resulting in a pulmonary ischemia with injured capillary walls and the release of inflammatory mediators [15]. All of this increases abnormalities in gas exchange and leads to closure of the small airways.
Thus, compared to on-pump, off-pump surgery was associated with a reduced inflammatory response and lower levels of circulating neutrophils and monocytes [16].

Furthermore, many studies have showed that procedures without EC have lower pulmonary complication rates, earlier extubations, shorter MV duration, and a lower incidence of pneumonia compared to those with ECC [17].

So it seems to be clear that the use of ECC has evident consequences for postoperative pulmonary function compared with other types of major surgery, and it appears to cause additional lung injury and a delay in pulmonary recovery, probably due to the damaging effects of the associated systemic inflammatory response.

On the other hand, some studies have found that offpump surgery was not always more beneficial than on-pump surgery, showing, as Groeneveld et al. demonstrated, that ECC is not always a determinant for the development of PDD [18].

2.3. Surgical Effects and Systemic Temperature. There are some factors associated exclusively with cardiac surgery that affects pulmonary function and contribute to de development of PPD, like the median sternotomy incision, hypothermia for myocardial protection, dissection of the internal mammary artery, and the use of cardiopulmonary bypass.

It is not clear the effect of median sternotomy incision on PPD. Studies comparing sternotomy incision with thoracotomy incision showed that the minimal interruption to the chest wall, less trauma, and negligible lung compression make sternotomy a relatively benign procedure [14]. Many other studies, like the ones from Barnas et al. [19] or Ranieri et al. [20], have also demonstrated that the sternotomy incision did not affect the mechanical properties of the chest wall.

Although patients with normothermia exhibited decreases in the shunt fraction, $\mathrm{PA}-\mathrm{a} \mathrm{O}_{2}$, and the alveolusarterial gradient of $\mathrm{CO}_{2}$; central temperature did not appear to significantly influence gas exchange (alveolar arterial difference in oxygen partial pressure, or PA-a $\mathrm{O}_{2}$ ) after an aortocoronary bypass graft. It suggests that normothermia might be beneficial in the preservation of pulmonary function after cardiopulmonary bypass surgery [21].

With all this, it seems clear that the severe pulmonary dysfunction developed after cardiac surgery is influenced by two main factors. One is the mechanical stress and biotrauma induced by the mechanical ventilation and the use of an inadequate ventilatory strategy with high volumes and low PEEP levels that stimulate atelectasis. Second is the exaggerated systemic inflammatory response to the cardiac surgery and its associated factors, like the effects of general anesthesia, sternotomy incision, topical cooling, and extracorporeal circulation.

2.4. Mechanical Ventilation (MV). Mechanical ventilation can cause significant changes in lung structure and function. This lung injury during mechanical ventilation induces pulmonary inflammation that can spread to distant organs and considerably affect treatment outcomes [22].

In addition to the MV lung injury, there are many factors involved in cardiac surgery that affect pulmonary function 
too and play an important role in this inflammatory response, including extra corporeal circulation (ECC), the surgical intervention, and injuries due to ischemia-reperfusion.

Ventilation-induced lung injury with pulmonary inflammation results from both mechanical and biological trauma [23].

Mechanical trauma involves both volutrauma and barotrauma. The term barotrauma is used to indicate lung damage attributable to the application of high airway pressure [24]; in this way, volutrauma is referred to the alveolar overdistension when using large tidal volumes. The stress produced by this mechanical trauma could be strong enough to cause destruction of the anatomical lung structure with epithelial injury, loss of epithelial integrity, and edema.

Biological trauma is referred to the biological reaction in response to mechanical ventilation stress. Ventilating with high tidal volume induces the release of inflammatory mediators that contribute to this ventilation-induced biotrauma [25] by activating both local and systemic inflammatory responses, what causes the release of cytokines and other soluble inflammatory mediators and the activation of complement, leukocytes, and endothelial cells, resulting in an alteration of the normal function of tissues and organs by altering cellular pathways.

Biotrauma results from the forces acting during mechanic ventilation with the cyclic opening and collapse of alveoli and its overdistension that induce the release of proinflammatory cytokines, recruitment of leucocytes, and local initiation of inflammatory processes. It still remains unclear how mechanical forces are translated into the biochemical signals that produce biotrauma [26]. According to the experimental studies, that have studied the relationship between mechanical distension of the alveolocapillary membrane and the production of mediators, the biotrauma hypothesis assumes that lung injury is caused by the release of this proinflammatory mediators and the excessive activation of the immune system; in this way, theories proposed imply mechanoreceptors, stretchsensitive channels, activation of inflammatory cascade [27], and activation of the transcription of the nuclear factor kappa [28] (NF- $\kappa \mathrm{B})$ which becomes the major factor of modification of nucleic acid sequence in the cell nucleus and synthesis of inflammatory factors (TNF- $\alpha$, IL-1 $\beta$, IL-6, and IL-8) [26].

Biotrauma causes diverse biological responses, like the action of oxygen free radicals, cellular mechanisms of growth or division and apoptosis, altered expression of genes and proteins, activation of coagulation cascade, and stimulation of various elements of the immune system, which lead consequently to the cascade of inflammation. And this exaggerated inflammatory response initiated locally in the pulmonary tissue may cross into the systemic circulation causing systemic inflammatory response [29].

The presence of atelectasis is one of the principal causes of PDD and a primary factor in the development of pulmonary inflammation [27], and there is a correlation between the amount of atelectasis and the intrapulmonary shunt [30].

Atelectasis is related with a too low end-expiratory lung volume and their development is associated with the loss of surfactant and the cyclic opening and collapse of unstable lung units, which is promoted by ventilation with zero or inadequate PEEP [31]. This repetitive collapse and reopening of alveoli is termed atelectrauma [32].

When the atelectatic lung units are exposed to high ventilating pressures, the alternate opening and collapsing of alveoli generate damaging transverse forces localised in these dependent parts. This transverse forces applied to the collapsed units could be sufficiently high to damage the airway epithelium and cause a "stress induced failure" of the alveolar capillary membrane resulting in an increased microvascular permeability, edema, and an influx of plasmatic proteins causing surfactant dysfunction and initiating an inflammatory reaction [33-35]. In this way, Dreyfuss et al. [35] demonstrated that volutrauma (ventilation with high tidal volumes producing high transpulmonary pressure) rather than barotrauma (ventilation with high pressures producing low transpulmonar pressure) was the primary determinant factor for pulmonary injury and inflammatory response.

\section{Therapeutic Measures That Minimize PPD after Cardiac Surgery}

3.1. Protective Ventilation Strategy: Open Lung Approach $(O L A)$. It is well studied that protective ventilation strategies can reduce the incidence of atelectasis and pulmonary infections in surgical patients [36]. The OLA ventilatory strategy was initially conceived to treat patients with ARS; its aim is to reduce the shear forces generated by the cyclic opening and closing of the atelectasic alveoli and minimize the development of diffuse alveolar damage, pulmonary edema, recruitment of inflammatory cells, and cytokines production $[37,38]$ of the injurious ventilation strategies with high tidal volume.

The OLA strategy has to be applied with recruiting maneuvers and sufficient PEEP to increase transpulmonary pressure enough for maintaining opened the maximum possible number of alveoli with minimum delta pressure (Pplateau-PEEP) to prevent pulmonary overdistension [39]. The low delta pressure is typically achieved by using low tidal volumes $(4-6 \mathrm{~mL} / \mathrm{kg})$. Serita et al. [40] found that individualised recruitment maneuvers, brought about an improvement in oxygenation and lung compliance in patients undergoing selective cardiac surgery.

Using OLA ventilatory strategy the sudden changes of volume in large alveolar zones are minimized [41] and atelectasis were not observed in CT-scans in healthy anesthetized children. This ventilatory strategy also attenuates the surfactant alterations, what in consequence reduce the loss of proteins in the alveoli [42].

As this strategy prevents the cyclic collapse of alveoli by splinting them open at end-expiration, the stress to the alveolocapillary membrane resulted to be limited. It was observed a decrease in the biochemical markers released by damaged cells after ventilation with high pressures that confirm this [43].

It is important to notice that applying an adequate PEEP level and preventing the collapse at end-expiration minimizes the inflammatory response and diminishes bacterial translocation [44]. Furthermore, two recent studies with patients undergoing abdominal surgery showed that 
pulmonary inflammation can be reduced [45] and procoagulant alveolar changes can be prevented [46] by using lower tidal volume and PEEP.

As many studies have demonstrated, OLA strategy has multiple advantages. Miranda et al. [47] showed that OLA ventilation (tidal volume $6 \mathrm{~mL} / \mathrm{kg}$, PEEP $14 \mathrm{~cm} \mathrm{H}_{2} \mathrm{O}$ ), applied immediately after intubation, significantly attenuates the inflammatory response by reducing IL-6, IL-8, IL-10, TNFalpha, and interferon-gamma plasma levels compared to conventional ventilation (tidal volume $8 \mathrm{~mL} / \mathrm{kg}$, PEEP $5 \mathrm{~cm}$ $\mathrm{H}_{2} \mathrm{O}$ ). During mechanical ventilation, the application of OLA was accompanied by significant increases in the $\mathrm{PaO}_{2} / \mathrm{FiO}_{2}$, suggesting a significant reduction in atelectasis [48]. These investigators found later [49] that the effect of OLA on pulmonary volume was maintained after extubation; the day after extubation, the group ventilated with OLA showed $40 \%$ higher FRC than those given conventional ventilation. This effect on the FRC was maintained until the 5th day after extubation. Also, the OLA group had a significant decrease in the incidence of hypoxemia $\left(\mathrm{SpO}_{2}<90 \%\right.$ with ambient air) on the day after extubation compared to the group with conventional ventilation.

Furthermore, Ranieri et al. [50] found in previous experimental findings in patients with ARDS, that the levels of tumor necrosis factor-alpha (TNF $\alpha$ ), interleukin-6 (IL6), and IL-8 in bronchoalveolar lavage (BAL) were lower with a ventilatory strategy titrated for optimal positive endexpiratory pressure (PEEP) and low tidal volumes than with a strategy that used high tidal volumes. In a multicentre study with 861 patients, ventilation with low tidal volumes $(6 \mathrm{~mL} / \mathrm{kg})$ diminished plasma concentrations of IL- 6 and significantly reduced the 28-day mortality of patients with ARDS. This suggested that the application of suitable ventilatory strategies clearly affected the development of an inflammatory response after cardiac surgery.

The OLA strategy has not been evaluated clinically in terms of outcomes (mortality or readmissions to the ICU). Even though, when the causes for readmission into the ICU after cardiac surgery were studied, Chung et al. [51] founded that after discharge from the ICU, the percent increase in the required fraction of inspired oxygen was correlated to an increased risk of readmission. Given that OLA strategy reduces the incidence of hypoxemia and increases FRC on discharge, these results suggested that it might reduce the incidence of ICU readmission.

On the other hand, OLA ventilatory strategy has some adverse effects that have been noticed. For example, high PEEP may detrimentally increase intracranial pressure and impair ventricular filling, the RV afterload is increased, but contractility is not affected $[52,53]$.

Cardiovascular effects are particularly prominent in patients who are fluid depleted.

Dyhr et al. [54] found that cardiac output was not affected by high PEEP levels after a recruitment maneuver in cardiac surgery patients. These results were later confirmed by Miranda et al. [55] who, using a pulmonary artery catheter in patients undergoing cardiac surgery, showed that OLA ventilation did not affect pulmonary vascular resistance or the RV ejection fraction.
As we said, high PEEP could increase RV afterload. Even so, high PEEP levels used during OLA ventilation probably did not affect RV afterload because atelectasis was avoided and low tidal volumes were used. This is because it has been shown that atelectasis caused a significant increase in RV afterload [56]. This effect is because of two different mechanisms, the local hypoxic pulmonary vasoconstriction induced in nonaerated lung areas [53] and the capillary compression due to the overdistension in aerated lung areas.

Several clinical and experimental studies suggested that OLA strategy and isolated recruitment maneuvers increased $\mathrm{RV}$ afterload in patients without a history of RV failure undergoing cardiac surgery [57, 58]. Additionally, Miranda et al. [55] showed, at the study we have mentioned before, that high PEEP levels during OLA ventilation did not decrease the RV preload when the patients had an adequate previous preload.

Even so, an exhaustive monitoring is absolutely necessary when isolated recruitment maneuvers are performed in patients with previous right cardiac failure. It is important to be extremely cautious with these patients, and avoid them if adverse events are predictable according to the monitored values.

Taking all these into account, our group recommends OLA strategy, initiating it after the intubation in the OR and continuing with this strategy until the patient is extubated. We support OLA in this context, as we have not found adverse effects and, as we have mentioned before, it has important potential advantages (like reducing ventilator-induced pulmonary inflammation, increasing the $\mathrm{PaO}_{2} / \mathrm{FiO}_{2}$, attenuating the postoperative reduction in FRC, and decreasing the incidence of hypoxemia).

3.2. Ventilation Strategy during ECC. Apnoea during ECC has been suggested to promote activation of lysosomal enzymes in the pulmonary circulation, which in turn are correlated with the incidence of postoperative pulmonary dysfunction [59]. Hipoventilation during ECC is associated with the development of microatelectasis, hydrostatic pulmonary edema, poor compliance, and an increased incidence of infection [60]. In this way, the hypothesis is that maintaining mechanical ventilation during ECC may limit postoperative pulmonary complications [61].

Atelectasis is the principal determinant in postoperative lung gas exchange and may play a larger role in ventilatory abnormalities after cardiac surgery than edema due to increased permeability.

To prevent all these complications, it has been applied some maneuvers such as the intermittent ventilation or application of continuous airway pressure (CPAP) during ECC $[62,63]$. CPAP application during CPB has been reported as an effective adjunct in some studies [63]. Loeckinger et al. [61] studied continuous positive airway pressure (CPAP) at $10 \mathrm{~cm} \mathrm{H}_{2} \mathrm{O}$ during ECC and the effect on postoperative pulmonary gas exchange. They found a significantly higher $\mathrm{PaO}_{2}$, a significantly lower PA-a $\mathrm{O}_{2} 4 \mathrm{~h}$ after ECC, and better gas exchange after extubation in the CPAP group compared to controls. More recently, John and Ervine [64] demonstrated in their randomized study that maintaining ventilation with 
a tidal volume of $5 \mathrm{~mL} / \mathrm{kg}$ during ECC provided other benefits compared to discontinued ventilation. They showed a decrease in extravascular lung water and a shorter extubation time in the ventilation group compared to controls. In this way, Davoudi et al. [65] showed in a prospective randomized study that a continued ventilation with low tidal volume during CPB improved post-by pass oxygenation and lung mechanics.

On the other hand, even though the use of CPAP [61], recruitment maneuvers [66], or low-tidal volume ventilation during CBP has demonstrated to decrease inflammation and improve oxygenation, lung mechanics, and shunt fraction, this positive effects have been shown to be transient with a questionable impact on the clinical outcome [67].

Another option proposed to attenuate lung dysfunction post-ECC is maintaining ventilation together with pulmonary artery perfusion during ECC. In this way, Friedman et al. [68] demonstrated in an experimental comparative study that ventilation with pulmonary artery perfusion during ECC might have benefits in preserving lung function by reducing platelet and neutrophil sequestration and attenuating the TXB2 response after ECC. On the other hand, another experimental study by Serraf et al. [69] showed no significant improvement in pulmonary vascular resistance, respiratory index, or oxygen tensions with continuous ventilation during ECC.

Based on these results, the evidence for clear benefits of maintining ventilation during ECC is not totally clear. Even so, continued ventilation with low frequency during ECC seems to be easy, safe, low-cost, and potentially quite beneficial and it has been suggested to be an easy method to implement with no additional cost.

\subsection{Early Extubation and Noninvasive Mechanical Ventilation.} As we said before, ventilation with a high tidal volume and low or none PEEP, in cardiac surgery patients, is associated with an inflammatory response that contributes to the ventilation induced biotrauma [25]. High tidal volume ventilation in the immediate postoperative period of cardiac surgery has been associated with prolonged mechanical ventilation, a longer ICU stay and an increased risk of organ dysfunction [70]. In this way, using low tidal volumes (of around $6 \mathrm{~mL} / \mathrm{Kg}$ ) and an adequate PEEP level in the intraoperative and postoperative period have been highly recommended to avoid lung collapse and diminished atelectasis. This could also reduce duration of mechanical ventilation and the reintubation rate [71].

Early extubation (less than 6-8h) after cardiac surgery has been shown to reduce complications in the postoperative period, as well as decrease in ICU stay and costs [69].

Camp et al. [72] demonstrated that an early extubation (within 9 hours after cardiac surgery) is associated with an improved outcome and have been shown to be the best predictor of uncomplicated recovery and a decreased late mortality after cardiac surgery.

Furthermore, a recent Cochrane review [73] concluded that early intubation is not associated with an increased risk of postoperative complications or reintubation and it produces a reduction of the length of ICU stay.
Atelectasis plays an important role in the development of postoperative respiratory failure [74]. Noninvasive mechanical ventilation (NIV) should be applied to prevent acute respiratory failure (ARF) in patients at high risk of developing it [75].

NIV has also been used to treat an established postoperative acute respiratory failure, although there are nonconclusive results [76] and it has not demonstrated to be clearly effective once ARF is already established [77].

Otherwise, preventive use of NIV or CPAP has demonstrated to reduce respiratory work and improve gas exchange, oxygenation and alveolar ventilation [78-80], and it could also be used to wean patients from mechanical ventilation [75]. If it is used correctly, NIV has been reported to reduce atelectasis and $\mathrm{PPD}$, and to diminish reintubation rates, length of stay in ICU, and hospital and ICU readmissions $[79,80]$.

\section{Conclusion}

PPD is a frequent and almost inevitable consequence of cardiac surgery whose incidence still remains unacceptably high nowadays. His pathogenesis is not clear, but many factors have been shown to be involved in its development. In this way, there are two principal mechanisms that have been identified as the fundamental causes for the development of PPD, one is the stress of the surgery and its associated factors (ECC, median sternotomy incision, hypothermia for myocardial protection, dissection of the internal mammary artery, etc.) that cause an important systemic inflammatory response. The other important factor is the lung injury caused by inflammation and aggravated by suboptimal mechanical ventilation.

Taking all this in to account, our group recommends the use of OLA strategy in patients undergoing cardiac surgery with an early initiation (after the orotracheal intubation), combining low tidal volumes (tidal volume $6 \mathrm{~mL} / \mathrm{kg}$ ) with recruitment maneuvers and the instauration of a PEEP of 8$14 \mathrm{~cm} \mathrm{H}_{2} \mathrm{O}$. Additionally, maintaining low frequency ventilation during ECC seems to be a quite promising strategy with important benefits in preserving lung function. With these two ventilatory procedures, we could probably attenuated the inflammatory response, improve gas exchange parameters and postoperative pulmonary functions with a better FRC, and reduce the incidence of readmission in UCI with a better outcome. And all these benefits could be achieved with almost a little or even no hemodynamic alterations.

Early extubation is well documented and should be the goal in adults after cardiac surgery, as it may reduce postoperative complications and decrease ICU stay and costs.

NIV applied early has shown to be effective in reducing atelectasias and PPD, minimising reintubation rates, length of stay in ICU, and hospital and ICU readmissions.

\section{Conflict of Interests}

The authors have no conflict of interests. 


\section{References}

[1] R. F. Piotto, F. B. Ferreira, F. C. Colósimo, G. S. da Silva, A. G. de Sousa, and D. M. Braile, "Independent predictors of prolonged mechanical ventilation after coronary artery bypass surgery," Brazilian Journal of Cardiovascular Surgery, vol. 27, no. 4, pp. 520-528, 2012.

[2] A. Kogan, J. Cohen, E. Raanani et al., "Readmission to the intensive care unit after 'fast-track' cardiac surgery: risk factors and outcomes," Annals of Thoracic Surgery, vol. 76, no. 2, pp. 503-507, 2003.

[3] D. P. Taggart, "Respiratory dysfunction after cardiac surgery: effects of avoiding cardiopulmonary bypass and the use of bilateral internal mammary arteries," European Journal of CardioThoracic Surgery, vol. 18, no. 1, pp. 31-37, 2000.

[4] F. S. Vargas, K. K. Uezumi, F. B. Janete et al., "Acute pleuropulmonary complications detected by computed tomography following myocardial revascularization," Revista do Hospital das Clinicas de Faculdade de Medicina da Universidade de Sao Paulo, vol. 57, no. 4, pp. 135-142, 2002.

[5] J. P. Wiener-Kronish, "Postoperative pleural and pulmonary abnormalities in patients undergoing coronary artery bypass grafts," Chest, vol. 102, no. 5, pp. 1313-1314, 1992.

[6] R. Wynne and M. Botti, "Postoperative pulmonary dysfunction in adults after cardiac surgery with cardiopulmonary bypass: clinical significance and implications for practice," The American Journal of Critical Care, vol. 13, no. 5, pp. 384-393, 2004.

[7] J. Milot, J. Perron, Y. Lacasse, L. Létourneau, P. C. Cartier, and F. Maltais, "Incidence and predictors of ARDS after cardiac surgery," Chest, vol. 119, no. 3, pp. 884-888, 2001.

[8] J. T. Christenson, J.-M. Aeberhard, P. Badel et al., "Adult respiratory distress syndrome after cardiac surgery," Cardiovascular Surgery, vol. 4, no. 1, pp. 15-21, 1996.

[9] G. Asimakopoulos, P. L. C. Smith, C. P. Ratnatunga, and K. M. Taylor, "Lung injury and acute respiratory distress syndrome after cardiopulmonary bypass," Annals of Thoracic Surgery, vol. 68, no. 3, pp. 1107-1115, 1999.

[10] S. C. Jenkins, S. A. Soutar, A. Forsyth, J. R. W. Keates, and J. Moxham, "Lung function after coronary artery surgery using the internal mammary artery and the saphenous vein," Thorax, vol. 44, no. 3, pp. 209-211, 1989.

[11] C. S. H. Ng, A. A. Arifi, S. Wan et al., "Ventilation during cardiopulmonary bypass: impact on cytokine response and cardiopulmonary function," Annals of Thoracic Surgery, vol. 85, no. 1, pp. 154-162, 2008.

[12] T. Meier, A. Lange, H. Papenberg et al., "Pulmonary cytokine responses during mechanical ventilation of noninjured lungs with and without end-expiratory pressure," Anesthesia \& Analgesia, vol. 107, no. 4, pp. 1265-1275, 2008.

[13] G. Hedenstierna, A. Strandberg, B. Brismar, H. Lundquist, L. Svensson, and L. Tokics, "Functional residual capacity, thoracoabdominal dimensions, and central blood volume during general anesthesia with muscle paralysis and mechanical ventilation," Anesthesiology, vol. 62, no. 3, pp. 247-254, 1985.

[14] M. A. Matthay and J. P. Wiener-Kronish, "Respiratory management after cardiac surgery," Chest, vol. 95, no. 2, pp. 424-434, 1989.

[15] J. R. Utley, "Pathophysiology of cardiopulmonary bypass: current issues," Journal of Cardiac Surgery, vol. 5, no. 3, pp. 177-189, 1990.

[16] R. Ascione, C. T. Lloyd, M. J. Underwood, A. A. Lotto, A. A. Pitsis, and G. D. Angelini, "Inflammatory response after coronary revascularization with or without cardiopulmonary bypass," Annals of Thoracic Surgery, vol. 69, no. 4, pp. 1198-1204, 2000.

[17] S. Al-Ruzzeh, S. George, M. Bustami et al., "Effect of offpump coronary artery bypass surgery on clinical, angiographic, neurocognitive, and quality of life outcomes: randomised controlled trial," The British Medical Journal, vol. 332, no. 7554, pp. 1365-1372, 2006.

[18] A. B. J. Groeneveld, E. K. Jansen, and J. Verheij, "Mechanisms of pulmonary dysfunction after on-pump and off-pump cardiac surgery: a prospective cohort study," Journal of Cardiothoracic Surgery, vol. 2, article 11, 2007.

[19] G. M. Barnas, R. J. Watson, M. D. Green et al., "Lung and chest wall mechanical properties before and after cardiac surgery with cardiopulmonary bypass," Journal of Applied Physiology, vol. 76, no. 1, pp. 166-175, 1994.

[20] V. M. Ranieri, N. Vitale, S. Grasso et al., "Time-course of impairment of respiratory mechanics after cardiac surgery and cardiopulmonary bypass," Critical Care Medicine, vol. 27, no. 8, pp. 1454-1460, 1999.

[21] I. Birdi, I. A. Regragui, M. B. Izzat et al., "Effects of cardiopulmonary bypass temperature on pulmonary gas exchange after coronary artery operations," Annals of Thoracic Surgery, vol. 61, no. 1, pp. 118-123, 1996.

[22] D. Dreyfuss and G. Saumon, "Ventilator-induced lung injury: lessons from experimental studies," The American Journal of Respiratory and Critical Care Medicine, vol. 157, no. 1, pp. 294323, 1998.

[23] M. García-Delgado, I. Navarrete-Sánchez, and M. Colmenero, "Preventing and managing perioperative pulmonary complications following cardiac surgery," Current Opinion in Anaesthesiology, vol. 27, no. 2, pp. 146-152, 2014.

[24] A. Kumar, H. Pontoppidan, K. J. Falke, R. S. Wilson, and M. B. Laver, "Pulmonary barotrauma during mechanical ventilation," Critical Care Medicine, vol. 1, no. 4, pp. 181-186, 1973.

[25] E. Zupancich, D. Paparella, F. Turani et al., "Mechanical ventilation affects inflammatory mediators in patients undergoing cardiopulmonary bypass for cardiac surgery: a randomized clinical trial," Journal of Thoracic and Cardiovascular Surgery, vol. 130, no. 2, pp. 378-383, 2005.

[26] S. Uhlig, "Ventilation-induced lung injury and mechanotransduction: stretching it too far?" The American Journal of Physiology_Lung Cellular and Molecular Physiology, vol. 282, no. 5, pp. L892-L896, 2002.

[27] U. Uhlig, J. J. Haitsma, T. Goldmann, D. L. Poelma, B. Lachmann, and S. Uhlig, "Ventilation-induced activation of the mitogen-activated protein kinase pathway," European Respiratory Journal, vol. 20, no. 4, pp. 946-956, 2002.

[28] J. M. Kyriakis and J. Avruch, "Mammalian mitogen-activated protein kinase signal transduction pathways activated by stress and inflammation," Physiological Reviews, vol. 81, no. 2, pp. 807869, 2001.

[29] L. Pinhu, T. Whitehead, T. Evans, and M. Griffiths, "Ventilatorassociated lung injury," The Lancet, vol. 361, no. 9354, pp. 332340, 2003.

[30] J. Verheij, A. van Lingen, P. G. H. M. Raijmakers et al., "Pulmonary abnormalities after cardiac surgery are better explained by atelectasis than by increased permeability oedema," Acta Anaesthesiologica Scandinavica, vol. 49, no. 9, pp. 1302-1310, 2005. 
[31] K. Kuchnicka and D. Maciejewski, "Ventilator-associated lung injury," Anaesthesiology Intensive Therapy, vol. 45, no. 3, pp. 164170, 2013.

[32] A. S. Slutsky, "Lung injury caused by mechanical ventilation," Chest, vol. 116, no. 1, supplement, pp. 9S-15S, 1999.

[33] J. J. Marini, "Ventilator-induced airway dysfunction?" The American Journal of Respiratory and Critical Care Medicine, vol. 163, no. 4, pp. 806-807, 2001.

[34] A. Esan, D. R. Hess, S. Raoof, L. George, and C. N. Sessler, "Severe hypoxemic respiratory failure: part 1-ventilatory strategies," Chest, vol. 137, no. 5, pp. 1203-1216, 2010.

[35] D. Dreyfuss, P. Soler, G. Basset, and G. Saumon, "High inflation pressure pulmonary edema. Respective effects of high airway pressure, high tidal volume, and positive end-expiratory pressure," The American Review of Respiratory Disease, vol. 137, no. 5, pp. 1159-1164, 1988.

[36] T. Tao, L. Bo, F. Chen et al., "Effect of protective ventilation on postoperative pulmonary complications in patients undergoing general anaesthesia: a meta-analysis of randomised controlled trials," BMJ Open, vol. 4, no. 6, Article ID e005208, 2014.

[37] C. Putensen, N. Theuerkauf, J. Zinserling, H. Wrigge, and P. Pelosi, "Meta-analysis: ventilation strategies and outcomes of the acute respiratory distress syndrome and acute lung injury," Annals of Internal Medicine, vol. 151, no. 8, pp. 566-576, 2009.

[38] M. Plataki and R. D. Hubmayr, "The physical basis of ventilatorinduced lung injury," Expert Review of Respiratory Medicine, vol. 4, no. 3, pp. 373-385, 2010.

[39] B. Lachmann, "Open up the lung and keep the lung open," Intensive Care Medicine, vol. 18, no. 6, pp. 319-321, 1992.

[40] R. Serita, H. Morisaki, and J. Takeda, "An individualized recruitment maneuver for mechanically ventilated patients after cardiac surgery," Journal of Anesthesia, vol. 23, no. 1, pp. 87-92, 2009.

[41] S. J. C. Verbrugge, V. Šorm, and B. Lachmann, "Mechanisms of acute respiratory distress syndrome: role of surfactant changes and mechanical ventilation," Journal of Physiology and Pharmacology, vol. 48, no. 4, pp. 537-557, 1997.

[42] A. Hartog, G. F. Vazquez de Anda, D. Gommers, U. Kaisers, and B. Lachmann, "At surfactant deficiency, application of 'the open lung concept' prevents protein leakage and attenuates changes in lung mechanics," Critical Care Medicine, vol. 28, no. 5, pp. 1450-1454, 2000.

[43] S. J. C. Verbrugge, J. W. de Jong, E. Keijzer, G. V. de Anda, and B. Lachmann, "Purine in bronchoalveolar lavage fluid as a marker of ventilation-induced lung injury," Critical Care Medicine, vol. 27, no. 4, pp. 779-783, 1999.

[44] S. J. C. Verbrugge, V. Šorm, A. van’t Veen, J. W. Mouton, D. Gommers, and B. Lachmann, "Lung overinflation without positive end-expiratory pressure promotes bacteremia after experimental Klebsiella pneumoniae inoculation," Intensive Care Medicine, vol. 24, no. 2, pp. 172-177, 1998.

[45] E. K. Wolthuis, G. Choi, M. C. Dessing et al., "Mechanical ventilation with lower tidal volumes and positive end-expiratory pressure prevents pulmonary inflammation in patients without preexisting lung injury," Anesthesiology, vol. 108, no. 1, pp. 46$54,2008$.

[46] G. Choi, E. K. Wolthuis, P. Bresser et al., "Mechanical ventilation with lower tidal volumes and positive end-expiratory pressure prevents alveolar coagulation in patients without lung injury," Anesthesiology, vol. 105, no. 4, pp. 689-695, 2006.
[47] D. R. Miranda, D. Gommers, A. Struijs et al., "Ventilation according to the open lung concept attenuates pulmonary inflammatory response in cardiac surgery," European Journal of Cardio-thoracic Surgery, vol. 28, no. 6, pp. 889-895, 2005.

[48] L. Magnusson, V. Zemgulis, S. Wicky, H. Tydén, and G. Hedenstierna, "Effect of CPAP during cardiopulmonary bypass on postoperative lung function. An experimental study," Acta Anaesthesiologica Scandinavica, vol. 42, no. 10, pp. 1133-1138, 1998.

[49] D. R. Miranda, A. Struijs, P. Koetsier et al., "Open lung ventilation improves functional residual capacity after extubation in cardiac surgery," Critical Care Medicine, vol. 33, no. 10, pp. 22532258, 2005.

[50] V. M. Ranieri, P. M. Suter, C. Tortorella et al., "Effect of mechanical ventilation on inflammatory mediators in patients with acute respiratory distress syndrome: a randomized controlled trial," The Journal of the American Medical Association, vol. 282, no. 1, pp. 54-61, 1999.

[51] D. A. Chung, L. D. Sharples, and S. A. M. Nashef, "A case-control analysis of readmissions to the cardiac surgical intensive care unit," European Journal of Cardio-Thoracic Surgery, vol. 22, no. 2, pp. 282-286, 2002.

[52] J.-M. Schmitt, A. Vieillard-Baron, R. Augarde, S. Prin, B. Page, and F. Jardin, "Positive end-expiratory pressure titration in acute respiratory distress syndrome patients: impact on right ventricular outflow impedance evaluated by pulmonary artery Doppler flow velocity measurements," Critical Care Medicine, vol. 29, no. 6, pp. 1154-1158, 2001.

[53] J. E. Berglund, E. Halden, S. Jakobson, and J. Landelius, "Echocardiographic analysis of cardiac function during high PEEP ventilation," Intensive Care Medicine, vol. 20, no. 3, pp. 174-180, 1994.

[54] T. Dyhr, N. Laursen, and A. Larsson, "Effects of lung recruitment maneuver and positive end-expiratory pressure on lung volume, respiratory mechanics and alveolar gas mixing in patients ventilated after cardiac surgery," Acta Anaesthesiologica Scandinavica, vol. 46, no. 6, pp. 717-725, 2002.

[55] D. R. Miranda, D. Gommers, A. Struijs et al., "The open lung concept: effects on right ventricular afterload after cardiac surgery," The British Journal of Anaesthesia, vol. 93, no. 3, pp. 327-332, 2004.

[56] M. Duggan, C. L. McCaul, P. J. McNamara, D. Engelberts, C. Ackerley, and B. P. Kavanagh, "Atelectasis causes vascular leak and lethal right ventricular failure in uninjured rat lungs," The American Journal of Respiratory and Critical Care Medicine, vol. 167, no. 12, pp. 1633-1640, 2003.

[57] J. Nielsen, M. Østergaard, J. Kjaergaard et al., "Lung recruitment maneuver depresses central hemodynamics in patients following cardiac surgery," Intensive Care Medicine, vol. 31, no. 9, pp. 1189-1194, 2005.

[58] S.-C. Lim, A. B. Adams, D. A. Simonson et al., "Transient hemodynamic effects of recruitment maneuvers in three experimental models of acute lung injury," Critical Care Medicine, vol. 32, no. 12, pp. 2378-2384, 2004.

[59] H. Müller, W. Hügel, H. J. Reifschneider, G. Horpacsy, A. Hannekum, and H. Dalichau, "Lysosomal enzyme activity influenced by various types of respiration during extracorporeal circulation," Thoracic and Cardiovascular Surgeon, vol. 37, no. 2, pp. 65-71, 1989.

[60] L. Magnusson, V. Zemgulis, S. Wicky, H. Tydén, S. Thelin, and G. Hedenstierna, "Atelectasis is a major cause of hypoxemia and 
shunt after cardiopulmonary bypass: an experimental study," Anesthesiology, vol. 87, no. 5, pp. 1153-1163, 1997.

[61] A. Loeckinger, A. Kleinsasser, K. H. Lindner, J. Margreiter, C. Keller, and C. Hoermann, "Continuous positive airway pressure at $10 \mathrm{~cm} \mathrm{H}_{2} \mathrm{O}$ during cardiopulmonary bypass improves postoperative gas exchange," Anesthesia \& Analgesia, vol. 91, no. 3, pp. 522-527, 2000.

[62] C. S. H. Ng, S. Wan, A. P. C. Yim, and A. A. Arifi, "Pulmonary dysfunction after cardiac surgery," Chest, vol. 121, no. 4, pp. 1269-1277, 2002.

[63] L. Magnusson, V. Zemgulis, A. Tenling et al., "Use of a vital capacity maneuver to prevent atelectasis after cardiopulmonary bypass: an experimental study," Anesthesiology, vol. 88, no. 1, pp. 134-142, 1998.

[64] L. C. H. John and I. M. Ervine, "A study assessing the potential benefit of continued ventilation during cardiopulmonary bypass," Interactive Cardiovascular and Thoracic Surgery, vol. 7, no. 1, pp. 14-17, 2008.

[65] M. Davoudi, A. Farhanchi, A. Moradi, M. H. Bakhshaei, and G. Safarpour, "The effect of low tidal volume ventilation during cardio-pulmonary bypass on postoperative pulmonary function," Journal of Tehran University Heart Center, vol. 5, no. 3, pp. 128-131, 2010.

[66] M. Scherer, S. Dettmer, D. Meininger et al., "Alveolar recruitment strategy during cardiopulmonary bypass does not improve postoperative gas exchange and lung function," Cardiovascular Engineering, vol. 9, no. 1, pp. 1-5, 2009.

[67] J.-U. Schreiber, M. D. Lancé, M. de Korte, T. Artmann, I. Aleksic, and P. Kranke, "The effect of different lung-protective strategies in patients during cardiopulmonary bypass: a meta-analysis and semiquantitative review of randomized trials," Journal of Cardiothoracic and Vascular Anesthesia, vol. 26, no. 3, pp. 448454, 2012.

[68] M. Friedman, F. W. Sellke, S. Y. Wang, R. M. Weintraub, and R. G. Johnson, "Parameters of pulmonary injury after total or partial cardiopulmonary bypass," Circulation, vol. 90, no. 5, pp. II262-II268, 1994.

[69] A. Serraf, M. Robotin, N. Bonnet et al., "Alteration of the neonatal pulmonary physiology after total cardiopulmonary bypass," Journal of Thoracic and Cardiovascular Surgery, vol. 114, no. 6, pp. 1061-1069, 1997.

[70] F. Lellouche, S. Dionne, S. Simard, J. Bussières, and F. Dagenais, "High tidal volumes in mechanically ventilated patients increase organ dysfunction after cardiac surgery," Anesthesiology, vol. 116, no. 5, pp. 1072-1082, 2012.

[71] S. Sundar, V. Novack, K. Jervis et al., "Influence of low tidal volume ventilation on time to extubation in cardiac surgical patients," Anesthesiology, vol. 114, no. 5, pp. 1102-1110, 2011.

[72] S. L. Camp, S. C. Stamou, R. M. Stiegel et al., "Can timing of tracheal extubation predict improved outcomes after cardiac surgery?" HSR Proceedings in Intensive Care \& Cardiovascular Anesthesia, vol. 1, no. 2, pp. 39-47, 2009.

[73] F. Zhu, A. Lee, and Y. E. Chee, "Fast-track cardiac care for adult cardiac surgical patients," Cochrane Database of Systematic Reviews, vol. 10, Article ID CD003587, 2012.

[74] P. J. Neligan, "Postoperative noninvasive ventilation," Anesthesiology Clinics, vol. 30, no. 3, pp. 495-511, 2012.

[75] L. Cabrini, V. P. Plumari, L. Nobile et al., "Non-invasive ventilation in cardiac surgery: a concise review," Heart, Lung and Vessels, vol. 5, no. 3, pp. 137-141, 2013.
[76] G. Landoni, A. Zangrillo, and L. Cabrini, "Noninvasive ventilation after cardiac and thoracic surgery in adult patients: a review," Journal of Cardiothoracic and Vascular Anesthesia, vol. 26, no. 5, pp. 917-922, 2012.

[77] M. García-Delgado, I. Navarrete, M. J. García-Palma, and M. Colmenero, "Postoperative respiratory failure after cardiac surgery: use of noninvasive ventilation," Journal of Cardiothoracic and Vascular Anesthesia, vol. 26, no. 3, pp. 443-447, 2012.

[78] P. Matte, L. Jacquet, M. van Dyck, and M. Goenen, "Effects of conventional physiotherapy, continuous positive airway pressure and non-invasive ventilatory support with bilevel positive airway pressure after coronary artery bypass grafting," Acta Anaesthesiologica Scandinavica, vol. 44, no. 1, pp. 75-81, 2000.

[79] A. Zarbock, E. Mueller, S. Netzer, A. Gabriel, P. Feindt, and D. Kindgen-Milles, "Prophylactic nasal continuous positive airway pressure following cardiac surgery protects from postoperative pulmonary complications: a prospective, randomized, controlled trial in 500 patients," Chest, vol. 135, no. 5, pp. 12521259, 2009.

[80] P. Pasquina, P. Merlani, J. M. Granier, and B. Ricou, “Continuous positive airway pressure versus noninvasive pressure support ventilation to treat atelectasis after cardiac surgery," Anesthesia \& Analgesia, vol. 99, no. 4, pp. 1001-1008, 2004. 


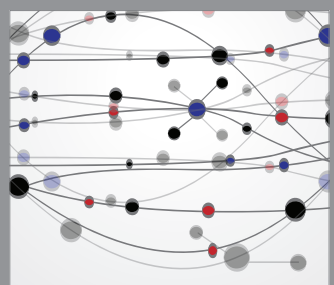

The Scientific World Journal
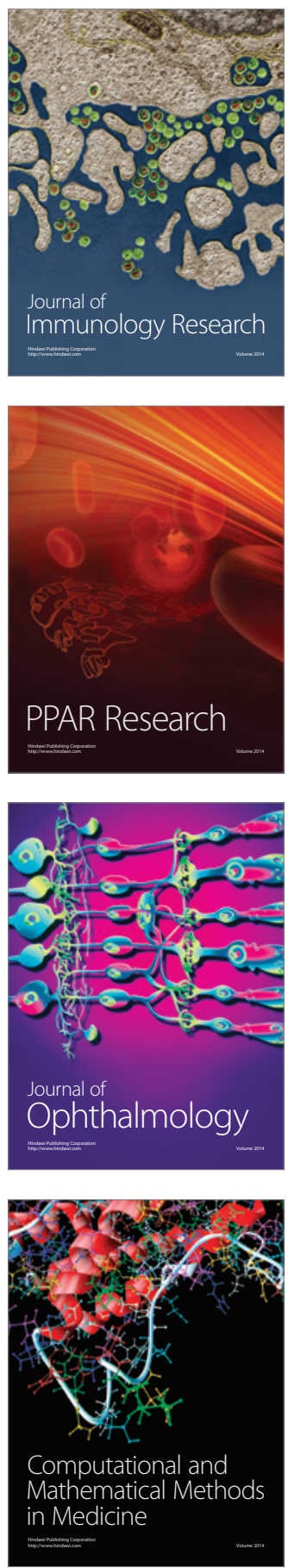

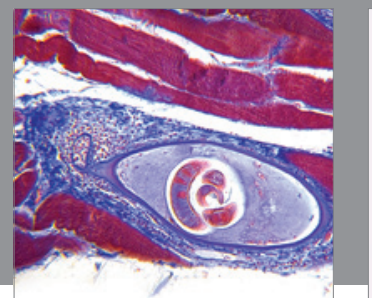

Gastroenterology

Research and Practice
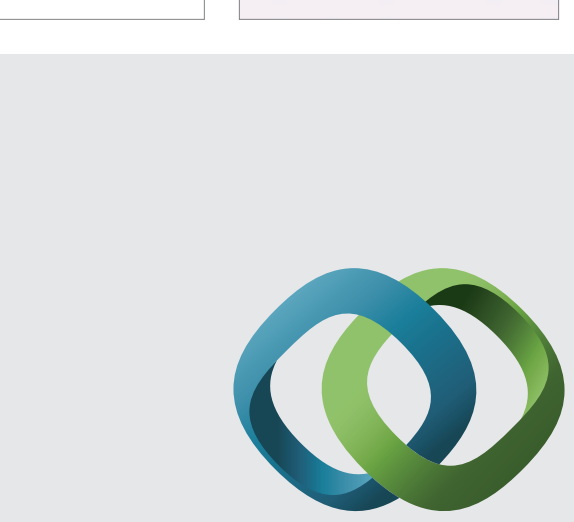

\section{Hindawi}

Submit your manuscripts at

http://www.hindawi.com
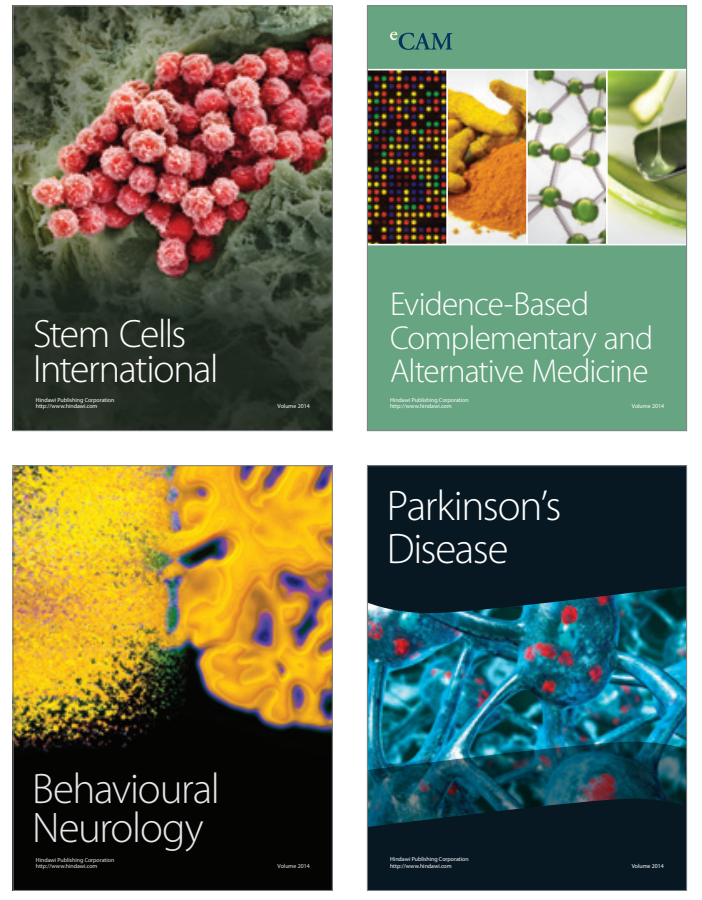
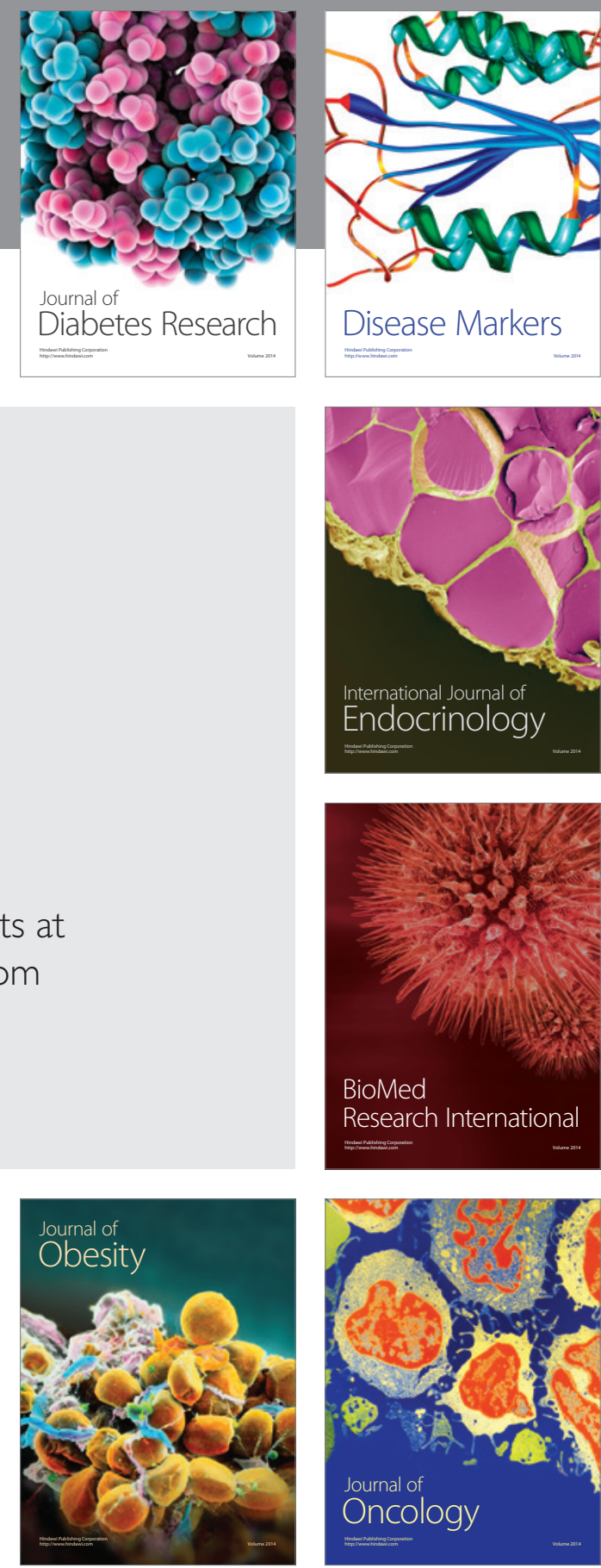

Disease Markers
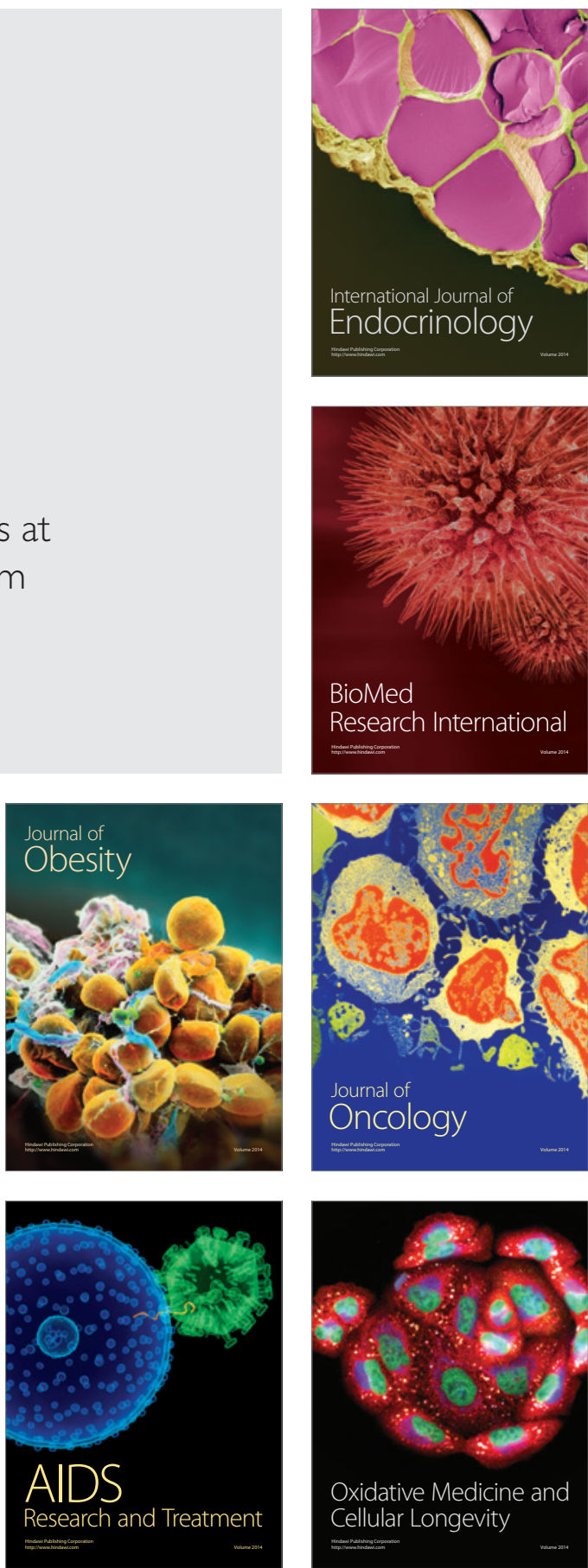